\title{
Hypodermic Needle In Main Bronchus: A Strange Case of Foreign Body
}

López V MD Ph D ; Ibañez C MD; Arévalo J MD Ph D; Arcas JJ MD ; Muñoz L MD Ph D; Fundación Jimenez Diaz, Madrid

\section{Background}

We frequently get patients with the lodgement of foreingn bodys in the aero-digestive tract. A variety of these have been reported but lower airway foreign matter is uncommonly encountered in adults'.

\section{Case Report}

-53 year old man

- Moderate hemoptysis

-Dysnea

- Cough

-Fever

-PA: Posttraumatic pneumothorax in 1985 due to a knife wound

\section{A rigid broncoscophy is performed...}
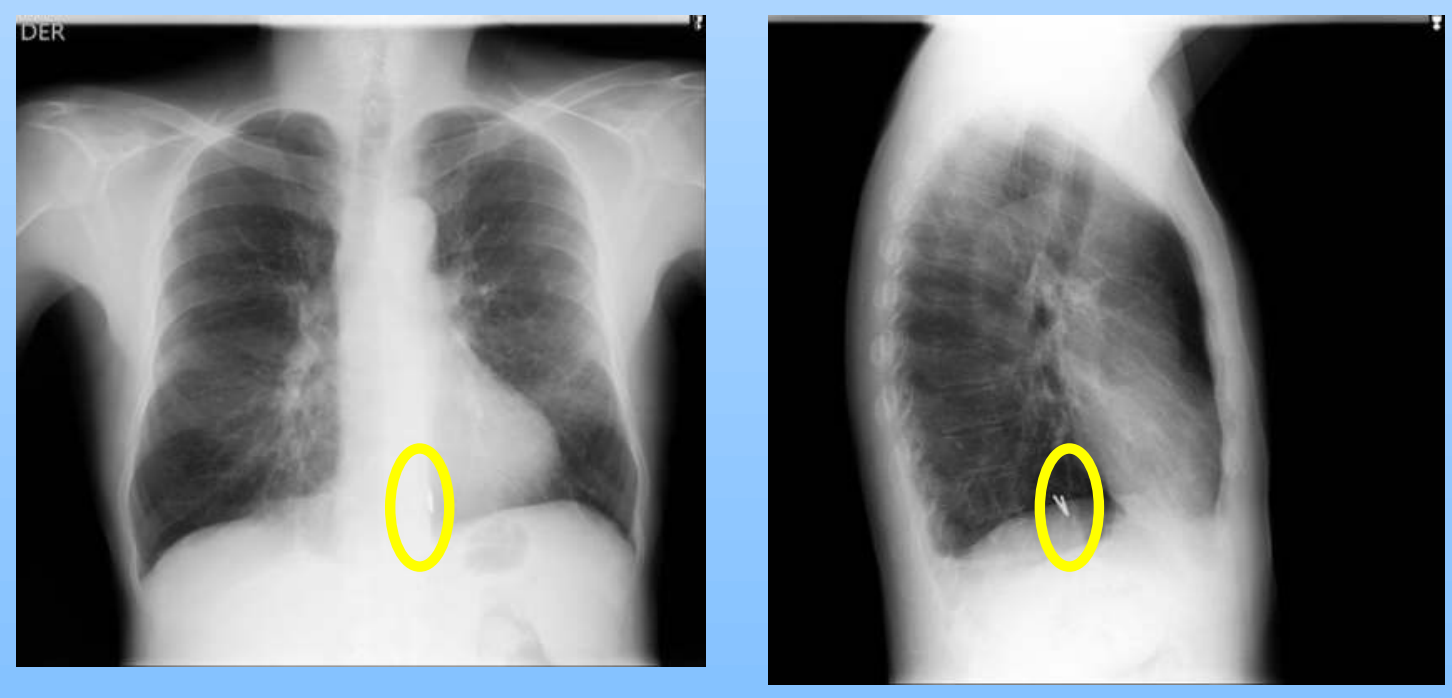

Chest X Ray: Metallic linear image

He was anesthetized with propofol, remifentanil and rocuronium, and ventilated with jet through a bronchoscope, where a foreign body was observed coming out from upper right lobe with a metal prolongation suggesting a needle, up to an intermediate bronchus. The needle was unclamped and extracted by broncoscope. After the extraction, an i-gel mask was introduced and the patient was extubated without incidents.

He was discharged the next day

\section{Discussion}
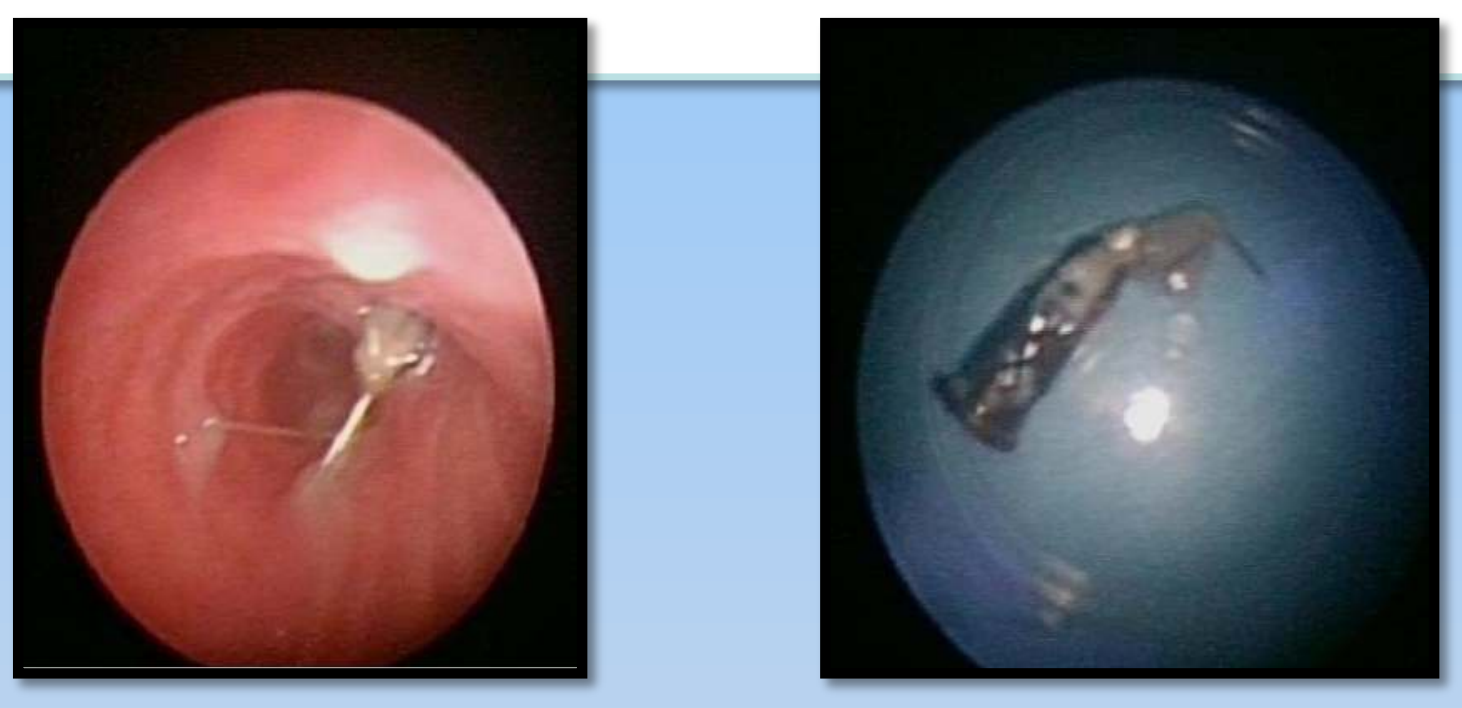

Foreign bodies are usual in children but infrequent in adults. The most common cause is aspiration, and although iatrogenic causes are rare, we can find from surgical gauzes to accupuncture needles. Surgical needles are extremely rare. In this patient, in a broncoscopy performed in 2014, the metallic material already existed, but located in the upper left lobe. It was interpreted as surgical osteosynthesis material, and it was not removed.

But the needle migrated to the contralateral lung, beginning to produce symptoms.

\section{Conclusion}

Foreign bodies in adults are mainly iatrogenic or traumatic. The recognition of atypical radiological features can help us to achieve correct diagnosis.

The removal of these objects usually involves the rapid recovery for the patient.

\section{References}

1.Hsu, A. Endoscopic intervention of lower airway foreign matter in adults a different perspective. Journal of Thoracic Disease,2015, 7, 10 (1870-1877)

2. Fidkowski CW, Zheng $\mathrm{H}$. The anesthetic considerations of tracheobronchial foreign bodies in children: a literature review of 12,979 cases. Anesth Analg. 2010 Oct ; 111 (4): 1016-25 